\title{
GÊNESE DA POLÍTICA NACIONAL DE FORMAÇÃO NO CONTEXTO DAS RECONFIGURAÇÕES DO ESTADO BRASILEIRO NO PERÍODO DE 2007 A 2010
}

\author{
GÉNESE DE LA POLÍTICA NACIONAL DE FORMACIÓN EN EL CONTEXTO DE \\ LAS RECONFIGURACIONES DEL ESTADO BRASILEÑO EN EL PERÍODO DE 2007 \\ A 2010
}

GENESIS OF THE NATIONAL TRAINING POLICY IN THE CONTEXT OF THE BRAZILIAN STATE RECONFIGURATIONS IN THE PERIOD 2007 TO 2010

\author{
Gislene Alves do AMARAL ${ }^{2}$ \\ Marcelo Soares Pereira da SILVA ${ }^{3}$
}

RESUMO: Neste trabalho analisamos o percurso de constituição de uma Política Nacional de Formação, considerando os elementos determinantes da sua gênese que podem ser destacados a partir das reconfigurações do Estado no período 2007 a 2010. Privilegiaram-se como base empírica as formas jurídico-normativas, expressas nos marcos regulatórios de sustentação das políticas. Iniciando pelo contexto do Plano de desenvolvimento da Educação, desenvolvemos a análise das mudanças promovidas no campo da formação de profissionais da educação e que resultaram nos atos normativos que instituíram a Política Nacional de Formação dos Profissionais da Educação Básica. O processo de formulação e implementação de políticas públicas não é linear, mas marcado por dinâmicas determinadas pela totalidade social e pelas mediações que conformam as singularidades que o campo implica, resultantes da correlação de forças dos atores sociais coletivos envolvidos. Os limites na construção de pactos sobre as políticas públicas em geral, e sobre as políticas de formação em particular, permitem compreender os percalços para se avançar na direção de "políticas de governo" para "políticas de Estado".

PALAVRAS-CHAVE: Formação dos profissionais da educação. Política nacional de formação. Políticas públicas.

RESUMEN: En este trabajo analizamos el curso de constitución de una Politica Nacional de Formación, considerando los elementos determinantes de su génesis que pueden trasladarse a partir de las reconfiguraciones del Estado en el período de 2007 2010. Se favoreció, come base empírica, las formas jurídico-normativas expresadas en los terminales regulatorios que dieron sustentación a las políticas. Al iniciar por el contexto del Plan de desarrollo de la Educación, desarrollamos el análisis de los cambios promovimos en el campo de la formación de profesionales de la educación y que resultó en los actos normativos que instituyeron la Política

\footnotetext{
${ }^{1}$ Observatório da Educação na FACED/UFU. "Pesquisa com apoio da FAPEMIG-APQ-01912-12"

${ }^{2}$ Universidade Federal de Uberlândia (UFU), Uberlândia - MG - Brasil. Professora da Faculdade de Educação Física, Doutora em Educação (UFU). ORCID <https://orcid.org/0000-0002-9556-556X>. E-mail: gislene.amaral@ufu.br

${ }^{3}$ Universidade Federal de Uberlândia (UFU), Uberlândia - MG - Brasil. Professor da Faculdade de Educação, Doutor em Educação (UNICAMP). ORCID <https://orcid.org/0000-0001-7668-5673>. E-mail: marcelospsilva@hotmail.com

RPGE- Revista on line de Política e Gestão Educacional, Araraquara, v. 23 n. 3, p. 498-522, set./dez., 2019. E-ISSN: 1519-9029. DOI: $10.22633 /$ rpge.v23i3.12526 (cc) BY-No-sA 
Nacional de Formación de los Profesionales de la Educación Básica. El proceso de formulación y aplicación políticas públicas no es lineal, sino señalado por dinámicos determinadas por la totalidad social y por mediações que conforma singularidades que el campo implica, resultados de la correlación de fuerzas de los protagonistas sociales colectivos implicados. Los límites en la construcción de pactos sobre las políticas públicas en general, y sobre las políticas de formación en particular, permiten incluir los beneficios para avanzarse en la dirección de "políticas del Gobierno" para "políticas de Estado".

PALABRAS CLAVE: Formación de los profesionales de la educación. Política nacional de formación. Políticas públicas.

ABSTRACT: In this work, we analyze the process of establishment of a National Training Policy, considering the determinant elements of its genesis, which can be highlighted from the reconfigurations of the State, from 2007 to 2010. The legal-normative forms expressed in the regulatory frameworks that gave support to the policies were given preference as an empirical basis. Starting from the context of the Education Development Plan, we developed the analysis of the changes promoted in the field of training of education professionals, which resulted in the normative acts that instituted the National Training Policy of Basic Education Professionals. The formulation and implementation of public policies isn't a linear process, but one marked by dynamics determined by the social totality and by the mediations that shape the singularities implied by the field, resulting from the correlation of forces of collective social involved. The limits in the construction of pacts on public policy in general, and particularly on the training policies, allow us to understand the struggles to move from "government policies" to "state policies".

KEYWORDS: National training policy. Training policy of basic education professionals. Public policies.

\section{Introdução}

No escopo deste texto, trataremos do percurso de constituição de uma Política Nacional de Formação, considerando os elementos determinantes da sua gênese que podem ser destacados a partir das reconfigurações do Estado ao longo do período estudado ${ }^{4}$. Esse período será aqui demarcado a partir do ano de 2007, no contexto do lançamento do Programa de Aceleração do Crescimento, em 2007, no bojo do qual foi delineado o Plano de Desenvolvimento da Educação.

Ao perseguir os modos de ser das políticas nacionais de formação dos profissionais da educação básica, privilegiou-se como base empírica as suas formas jurídico-normativas,

${ }^{4}$ Este estudo se constitui em um recorte de tese doutorado que teve como objeto de análise as políticas nacionais de formação dos profissionais da educação básica no período de 1996 a 2015, a qual estava se vinculada ao Projeto FAPEMIG - APQ 01912-12.

RPGE- Revista on line de Política e Gestão Educacional, Araraquara, v. 23 n. 3, p. 498-522, set./dez., 2019. E-ISSN: 1519-9029. DOI: $10.22633 /$ rpge.v23i3.12526 
expressas nos marcos regulatórios que lhes deram sustentação. A forma jurídica é entendida como instrumento político-ideológico (no sentido rigoroso e amplo de visão, ou concepção, de mundo) orientador de um poder constituído historicamente (portanto, de uma relação social), o Estado capitalista na formação social brasileira, em distintas conjunturas, cujo papel tem sido o da produção e reprodução da ordem social que lhe é correlata, a capitalista. Esse poder se expressa, dentre outras dimensões, em acordos, contratos, concertos, normas que regulam os comportamentos e as formas necessárias para que determinado tipo de sociabilidade se reproduza na direção da lógica dominante.

As formas jurídicas - sua forma e conteúdo -, no eixo da perspectiva histórica, permitem uma compreensão da lei e da norma que configuram e regulam diferentes esferas da totalidade social. As políticas educacionais, como forma jurídica e ideológica, são expressão dessa totalidade e não podem ser analisadas fora do movimento dialético do real, em suas determinações concretas. A forma político-educacional como instrumento ideológico orientador de um poder constituído, com suas formas jurídicas reais e concretas, "representa" um Estado de direito, constituído historicamente (TORRIGLIA e ORTIGARA, 2014).

\section{Plano de Desenvolvimento da Educação e o contexto das políticas de formação no período de 2007 a 2010}

Em 2007, Lula da Silva tomou posse para um segundo mandato à frente do Executivo federal. Com o objetivo de acelerar o ritmo da economia brasileira e de retomar o crescimento econômico, foi instituído, logo no primeiro mês de governo, o Programa de Aceleração do Crescimento - PAC 5 . Esse programa incorporou inovações na gestão dos recursos orçamentários dos projetos estratégicos, especialmente em setores estruturantes do país, e ampliou as funções de coordenação da ação governamental, mantendo os fundamentos macroeconômicos (inflação, consistência fiscal e solidez nas contas externas).

O PAC colocou, na ordem do dia, a agenda de um novo desenvolvimento e implementou medidas institucionais visando elevar o desempenho de áreas como produção industrial de bens de capital, mercado de consumo e geração de emprego, renda e massa salarial, e comércio varejista. A política econômica e social buscava um modelo de crescimento dentro dos limites do capitalismo brasileiro, com alguma transferência de renda, sem, contudo, romper claramente com os limites dados pelo modelo econômico neoliberal ainda vigente no país. Buscava-se

${ }^{5}$ As informações sobre o PAC foram retiradas de: http://www.pac.gov.br/sobre-o-pac

RPGE- Revista on line de Política e Gestão Educacional, Araraquara, v. 23 n. 3, p. 498-522, set./dez., 2019. E-ISSN: 1519-9029. 
promover um desenvolvimento nos moldes do chamado "neodesenvolvimentismo", pautado pelo equilíbrio entre crescimento econômico e social, com a formalização do emprego e a intervenção estatal ${ }^{6}$.

Analisando esse movimento de "refuncionalização do desenvolvimentismo", considerando seus impactos nas políticas socioambientais, na particularidade brasileira, Simião, Silva e Lima (2014, p. 364) afirmam que

Nos marcos do neoliberalismo contemporâneo, observa-se no Brasil um
momento em que o Estado mantém a característica de transferência de
recursos ao setor privado, sobretudo por meio da expansão do agronegócio e
dos projetos energéticos e de infraestrutura, a exemplo do Programa de
Aceleração do Crescimento (PAC) (MENDONÇA, 2012). Ou seja, em termos
econômicos não se observa diferenças entre o neoliberalismo e o chamado
neodesenvolvimentismo - processo em que este representa senão um novo
"padrão de desenvolvimento capitalista no interior da temporalidade histórica
do capitalismo global ou bloco histórico do mercado mundial sob o regime de
acumulação flexível predominantemente financeirizado".

Também no campo da educação, nesse início de segundo mandato, importantes movimentos se desenrolaram. Dentre eles, destaca-se o anúncio do Plano de Desenvolvimento da Educação - $\mathrm{PDE}^{7}$, que foi apresentado como o PAC da Educação, tendo como objetivo melhorar a qualidade da educação no país, com foco prioritário na educação básica. O então ministro da Educação, Fernando Haddad, publicou o documento intitulado "O PDE - razões, princípios e programas", no qual defendia que o PDE não seria uma instrumentalização do PNE, nem se limitava a apresentar diagnósticos dos problemas educacionais. O plano pretendia estabelecer um conjunto de ações que solucionariam problemas educacionais no Brasil, abrigando todos os programas desenvolvidos pelo MEC à época. É possível perceber nele uma ênfase substancial na educação básica, pois, das 30 ações estabelecidas pelo plano, 17 estavam focadas nela, como o Fundo de Manutenção e Desenvolvimento da Educação Básica e de Valorização dos Profissionais da Educação - Fundeb, o Índice de Desenvolvimento da Educação Básica - Ideb, o Piso Salarial do Magistério, entre outros programas de apoio, como “Transporte Escolar”, “Luz para Todos”, “Saúde nas Escolas”, “Guias de Tecnologias”, "Censo pela Internet", "Mais educação", “Coleção Educadores" e "Inclusão Digital”. Como não poderia deixar de ser, o estímulo à formação de professores também constituiu uma das ações

${ }^{6}$ Sobre as características do neodesenvolvimentismo e seus contornos no modelo brasileiro, consultar: ALVES (2013).

${ }^{7}$ Ao lado do anúncio do PDE, os debates e embates em torno da regulamentação do Fundeb, definido com base na E.C. no 53/2006, continuaram e culminaram na aprovação da Lei n' 11.494 , de 20 de junho de 2007.

RPGE- Revista on line de Política e Gestão Educacional, Araraquara, v. 23 n. 3, p. 498-522, set./dez., 2019. E-ISSN: 1519-9029. 
propostas por meio do Plano Nacional de Formação de Professores da Educação Básica Parfor.

Ainda no contexto do PDE, foi publicado o Decreto $n^{\circ}$. 6.094, de 24 de abril de 2007, que implementou o Plano de Metas Compromisso Todos pela Educação, cuja agenda havia sido lançada no ano anterior como uma iniciativa da sociedade civil que traduziu o movimento de um aglomerado de grupos empresariais preocupados com a educação básica ${ }^{8}$. O Plano de Metas foi apresentado como sendo uma "a conjugação dos esforços da União, Estados, Distrito Federal e Municípios, atuando em regime de colaboração, das famílias e da comunidade, em proveito da melhoria da qualidade da educação básica". Dentre as 28 (vinte e oito) diretrizes que o orientam, 4 (quatro) dizem respeito à formação de profissionais da educação básica:

XII - instituir programa próprio ou em regime de colaboração para formação inicial e continuada de profissionais da educação;

XIII - implantar plano de carreira, cargos e salários para os profissionais da educação, privilegiando o mérito, a formação e a avaliação do desempenho; XIV - valorizar o mérito do trabalhador da educação, representado pelo desempenho eficiente no trabalho, dedicação, assiduidade, pontualidade, responsabilidade, realização de projetos e trabalhos especializados, cursos de atualização e desenvolvimento profissional;

$\mathrm{XV}$ - dar consequência ao período probatório, tornando o professor efetivo estável após avaliação, de preferência externa ao sistema educacional local.

O Decreto ${ }^{\circ}$ 6.094/2007 regulamentou o Ideb como mecanismo para aferir a qualidade da Educação Básica e acompanhar as ações em prol do alcance de tais metas. De modo a viabilizar o apoio técnico e financeiro e participar do compromisso, os municípios e unidades federadas deveriam elaborar, com base na realidade local, um Plano de Ações Articuladas assinando um Termo de Adesão voluntária.

O MEC tinha como esfera de atuação nessa política a avaliação dos acordos com os entes federados, a fim de atestar o cumprimento das metas previstas nestes, criando, para essa finalidade, um Comitê Nacional de Compromisso Todos Pela Educação. Para que os entes federados pudessem aderir ao Plano de Metas, deveriam elaborar seu Plano de Ações Articuladas - PAR, contendo um diagnóstico das necessidades em 4 (quatro) dimensões: I - gestão educacional; II - formação de professores e profissionais de serviços e apoio escolar; III - recursos pedagógicos; IV - infraestrutura física. ${ }^{9}$

${ }^{8}$ Fizeram/fazem parte desse movimento: Fundação Bradesco, Itaú Social, Instituto Unibanco, Fundação Leman, Instituo Península, Fundação Vivo, Instituto Natura, Milú Vilela, Marcelo Kishmoto https://www.todospelaeducacao.org.br/pag/o-todos/\#bloco_67.

${ }^{9}$ Posteriormente, o PAR passou a ser regulamentado pela Lei n ${ }^{\circ} 12.695$, de 25 de julho de 2012.

RPGE- Revista on line de Política e Gestão Educacional, Araraquara, v. 23 n. 3, p. 498-522, set./dez., 2019. E-ISSN: 1519-9029. DOI: $10.22633 /$ rpge.v23i3.12526 
No campo da formação de professores, todos os programas e ações que vinham sendo desenvolvidos pelo Executivo federal foram incorporados e passaram a compor o escopo do PDE anunciado em abril de $2007^{10}$. Aqui, defrontamo-nos com uma estratégia por parte do MEC de dar continuidade a esses programas e ações de formação implementados no mandato anterior e de ampliar e aprofundar o campo de inserção e alcance desses programas.

Nesses primeiros anos do segundo mandato de Lula da Silva, o PDE/Plano de Metas/PAR representou o aprofundamento de um sistema de participação social que já incluíra diversos canais de interlocução entre sociedade e Estado, como as conferências, fóruns e audiências públicas. Também no interior do aparato do Estado, foram instituídos conselhos de natureza consultiva, como o Conselho de Desenvolvimento Econômico e Social - CDES, cuja função era "assessorar o Presidente da República na formulação de políticas e diretrizes específicas, e apreciar propostas de políticas públicas, de reformas estruturais e de desenvolvimento econômico e social que lhe sejam submetidas pelo Presidente da República, com vistas na articulação das relações de governo com representantes da sociedade" $"$.

Martins (2009) sinaliza que a proposta de criação do CDES foi resultado de estratégias de alianças anteriores à primeira eleição de Lula da Silva, que contaram com a importante participação do empresariado capitaneado pela presença de José de Alencar na vice-presidência da República.

Apesar de ser incensado como um grande programa de concertação entre Estado e sociedade civil, o fato é que o PDE e, no seu âmbito, o Plano de Metas Compromisso Todos pela Educação, não contou, no seu processo de formulação, com a participação de entidades científicas e sindicais, nem com representantes dos estados e municípios. Segundo Camini (2010, p. 539):

${ }^{10}$ Dentre esses programas destacam-se Programa Nacional Biblioteca na Escola (PNBE) e Programa Nacional do Livro Didático (PNLD) ; Programa Brasil Alfabetizado; Institucionalização do censo escolar da educação básica via internet - Educacenso; Plano de Expansão da Rede Federal de Educação Tecnológica; Programa Dinheiro Direto na Escola (PDDE); Sistema Universidade Aberta do Brasil (UAB); Fundo de Manutenção e Desenvolvimento da Educação Básica e de Valorização dos Profissionais da Educação - Fundeb; Programa Luz para Todos na Escola; Fies e Prouni; Programa Incluir: acessibilidade na educação superior; Coleção Educadores; Concursos públicos para os Institutos Federais de Educação Profissional e Tecnológica (Ifets) e para o Fundo Nacional de Desenvolvimento da Educação (FNDE); Programa de Acompanhamento e Monitoramento do Acesso e Permanência na Escola das Pessoas com Deficiência Beneficiárias do Benefício de Prestação Continuada da Assistência Social - BPC/Loas; Fomento à educação profissional; Programa de Apoio a Planos de Reestruturação e Expansão das Universidades Federais - Reuni; Regulamentação do estágio; Olimpíada Brasileira da Língua Portuguesa; Tecnologias educacionais; Inclusão digital; Programa Mais Educação; Olhar Brasil; Piso Salarial dos Profissionais do Magistério da Educação Básica; Programa Nacional de Pós-Doutorado (PNPD); Professor equivalente; Programa Nacional de Reestruturação e Aquisição de Equipamentos para a Rede Escolar Pública de Educação Infantil - Proinfância; Avaliação da alfabetização "Provinha Brasil"; Salas multifuncionais e qualificação de professores.

${ }^{11}$ Disponível em: http://www.cdes.gov.br/conteudo/41/o-que-e-o-cdes.html. Acesso em: 05/2018. 
De maneira geral, verificou-se a elaboração de um plano sem ampla consulta e debate com as entidades científicas e sindicais do campo educacional - as quais tiveram reconhecidamente presença destacada nos debates e na elaboração de projetos educacionais nas últimas décadas no Brasil. Nesse sentido, não foi considerado o acúmulo histórico produzido pelos educadores organizados em suas entidades através do Fórum Nacional em defesa da Escola Pública, as pautas discutidas e aprovadas em inúmeras conferências e congressos, as quais foram discutidas e legitimadas pela sociedade desde o processo constituinte em 1987-1988.

A influência do governo central no direcionamento de projetos e ações educacionais contaria com o consentimento dos entes federativos, condicionados, no entanto, pelos critérios de adesão estabelecidos. Esse protagonismo do governo central se evidencia, também, pela forte presença da ideia de planos nacionais que teriam no MEC um importante ator, não apenas na concepção desses planos, mas também em sua implementação, controle e avaliação (CAMINI, 2010). Nesse sentido, o PDE reafirma a lógica de accountability como a perspectiva que orientará as políticas de avaliação, cada vez mais atreladas a aspectos como controle e regulação típicos de um Estado gerencial.

Conforme sinaliza Dourado (2007, p. 928):

O PDE apresenta indicações de grandes e importantes ações direcionadas à educação nacional. No entanto, não está balizado por fundamentação técnicopedagógica suficiente e carece de articulação efetiva entre os diferentes programas e ações em desenvolvimento pelo próprio MEC e as políticas propostas. Tal constatação revela a necessidade de planejamento sistemático, que, após avaliar o conjunto de ações, programas e planos em desenvolvimento, contribua para o estabelecimento de políticas que garantam organicidade entre as políticas, entre os diferentes órgãos do MEC, sistemas de ensino e escola e, ainda, a necessária mediação entre o Estado, demandas sociais e o setor produtivo, em um cenário historicamente demarcado pela fragmentação e/ou superposição de ações e programas, o que resulta na centralização das políticas de organização e gestão da educação básica no país.

\section{A nova Capes e a formação dos profissionais da educação básica}

Nesse movimento de articulação e atuação do Executivo federal no campo da formação dos profissionais da educação, destaca-se, ainda, a reorganização da Coordenação de Aperfeiçoamento de Pessoal de Nível Superior - Capes, que viria a se confirmar por intermédio da Lei $\mathrm{n}^{\mathrm{o}} 11.502$, de 11 de julho de 2007, colocando um novo ator institucional nesse campo.

Essa lei acrescentará às tarefas institucionais da Capes a atuação também na formação inicial e continuada dos profissionais da educação básica. Nesse sentido, criará, no âmbito dessa instituição, o "Conselho Técnico-Científico da Educação Básica”, estabelecendo que

RPGE- Revista on line de Política e Gestão Educacional, Araraquara, v. 23 n. 3, p. 498-522, set./dez., 2019. E-ISSN: 1519-9029. DOI: $10.22633 /$ rpge.v23i3.12526 
§ 2o No âmbito da educação básica, a Capes terá como finalidade induzir e fomentar, inclusive em regime de colaboração com os Estados, os Municípios e o Distrito Federal e exclusivamente mediante convênios com instituições de ensino superior públicas ou privadas, a formação inicial e continuada de profissionais de magistério, respeitada a liberdade acadêmica das instituições conveniadas, observado, ainda, o seguinte:

I - na formação inicial de profissionais do magistério, dar-se-á preferência ao ensino presencial, conjugado com o uso de recursos e tecnologias de educação a distância;

II - na formação continuada de profissionais do magistério, utilizar-se-ão, especialmente, recursos e tecnologias de educação a distância.

Para cumprir essa tarefa, o Decreto $\mathrm{n}^{\circ}$ 6.316, de 20 de dezembro de 2007, ao definir um novo estatuto para a Capes, indicou, no $\S 2^{\circ}$ do art. $2^{\circ}$, as ações por meio da quais a Capes cumpriria sua nova finalidade no âmbito da educação básica:

I - fomentar programas de formação inicial e continuada de profissionais do magistério para a educação básica com vistas à construção de um sistema nacional de formação de professores;

II - articular políticas de formação de profissionais do magistério da educação básica em todos os níveis de governo, com base no regime de colaboração;

III - planejar ações de longo prazo para a formação inicial e continuada dos profissionais do magistério da educação básica em serviço;

IV - elaborar programas de atuação setorial ou regional, de forma a atender à demanda social por profissionais do magistério da educação básica;

$\mathrm{V}$ - acompanhar o desempenho dos cursos de licenciatura nas avaliações conduzidas pelo Instituto Nacional de Estudos e Pesquisas Educacionais Anísio Teixeira - INEP;

VI - promover e apoiar estudos e avaliações necessários ao desenvolvimento e melhoria de conteúdo e orientação curriculares dos cursos de formação inicial e continuada de profissionais de magistério;

VII - manter intercâmbio com outros órgãos da Administração Pública do País, com organismos internacionais e com entidades privadas nacionais ou estrangeiras, visando promover a cooperação para o desenvolvimento da formação inicial e continuada de profissionais de magistério, mediante a celebração de convênios, acordos, contratos e ajustes que forem necessários à consecução de seus objetivos.

Esse decreto criou novas instâncias organizacionais diretamente vinculadas a esse novo campo de atuação da Capes, criando duas novas diretorias: a Diretoria de Educação Básica Presencial e a Diretoria de Educação a Distância, instituindo ainda o Conselho TécnicoCientífico - CTC da Educação Básica com a seguinte composição:

I - o Presidente da CAPES, que o presidirá;

II - os Secretários de Educação Básica, de Educação Superior, de Educação Profissional e Tecnológica, de Educação a Distância, de Educação Especial e de Educação Continuada, Alfabetização e Diversidade do Ministério da Educação;

III - os Diretores de Educação Básica Presencial, de Ensino a Distância, de Avaliação e de Relações Internacionais da CAPES; e 
IV - até vinte representantes da sociedade civil escolhidos dentre profissionais de reconhecida competência em Educação Básica, observada a representatividade regional e por área de formação, quando possível (Art. 10).

Quanto à competência do CTC da Educação Básica, o art. 14 do decreto em questão definiu as seguintes tarefas:

Art. 14. Ao Conselho Técnico-Científico da Educação Básica compete:

I - assistir à Diretoria-Executiva na elaboração das políticas e diretrizes específicas de atuação da CAPES no tocante à formação inicial e continuada de profissionais do magistério da educação básica e a construção de um sistema nacional de formação de professores;

II - assistir às Diretorias de Educação Básica Presencial e de Educação a Distância no que diz respeito à consolidação do regime de colaboração entre todos os níveis de governo;

III - discutir diretrizes de longo prazo para a formação inicial e continuada dos profissionais do magistério da educação básica em serviço;

IV - fixar parâmetros para avaliação da demanda por profissionais do magistério da educação básica, inclusive para subsidiar a instalação de pólos municipais de apoio presencial;

$\mathrm{V}$ - acompanhar a avaliação dos cursos de pedagogia, licenciatura e normal superior nos processos de avaliação conduzidos pelo INEP;

VI - manifestar-se nos processos de reconhecimento e de renovação de reconhecimento de cursos de pedagogia, licenciatura e normal superior, previamente à decisão da Secretaria competente;

VII - colaborar na elaboração de propostas, relativas à formação inicial e continuada de profissionais de magistério da educação básica, para subsidiar o Plano Nacional de Educação;

VIII - opinar sobre a programação anual da CAPES, na área específica da Educação Básica;

IX - opinar sobre critérios e procedimentos para fomento a estudos e pesquisas relativos à orientação e conteúdo curriculares dos cursos de formação inicial e continuada de profissionais do magistério da educação básica;

$\mathrm{X}$ - estabelecer parâmetros mediante os quais serão avaliados os programas de fomento e os cursos que receberem recursos financeiros da CAPES;

XI - propor a realização de estudos e programas para o aprimoramento das atividades da CAPES na sua área de atuação;

XII - opinar sobre assuntos que lhe sejam submetidos pelo Presidente da CAPES; e

XIII - eleger seu representante no Conselho Superior.

As novas atribuições e a estrutura organizacional da Capes nos possibilitam apreender elementos que evidenciam o lugar e o papel do Estado no campo das políticas públicas e, mais especificamente, das políticas de formação de professores. Desde 2006, o MEC vinha redirecionando as políticas de formação no sentido de romper com a fragmentação e a dispersão dessas políticas. Referências a essa perspectiva em construção podem ser encontradas, por exemplo, na proposição da Rede Nacional de Formação Continuada e nos documentos sobre o Sistema UAB. 
Em maio de 2007, o Ministério da Educação publicou um relatório produzido por uma comissão especial instituída para estudar medidas que visassem a superar o déficit docente no ensino médio. O documento foi denominado "Escassez de professores no Ensino Médio: propostas estruturais e emergenciais" (RUIZ; RAMOS; HINGEL, 2007). Dentre as principais causas identificadas para o problema abordado, além da baixa remuneração docente e da pouca atratividade da carreira, o documento aponta os baixos índices de concluintes de cursos de licenciatura diante da demanda de professores nos sistemas estaduais de ensino. Uma das propostas apontadas pelo referido relatório é a defesa pela instituição de uma "política nacional de formação de professores":

Instituir uma política nacional de formação de professores é condição inerente ao Sistema Nacional de Educação, dele se beneficiando na medida em que se estabeleçam formas e mecanismos de cooperação entre os entes federativos, e, ao mesmo tempo, contribuindo para fortalecê-lo pela qualificação de seus agentes. Essa política deve ter metas ambiciosas, recursos financeiros adequados e ter por base programas e ações para formação, aperfeiçoamento, avaliação e promoção dos recursos humanos no campo da educação pública. Os programas e as ações abrangidos por essa política devem contemplar a criação de centros de formação inicial e continuada em todos os estados, regiões metropolitanas e outras consideradas de importância estratégica, com estabelecimento de metas a serem cumpridas pelos estados e municípios, bem como pela concertação política visando à definição de padrões e incentivos a serem inseridos nos planos de carreira de estados e municípios. As ações dessa política deverão, ainda, balizar-se pelo conceito de redes de ação e de cooperação, de forma a criar condições para a atuação integrada dos sistemas de ensino, das instituições de Ensino Superior, dos centros de pesquisas voltados para a Educação e das organizações sociais (RUIZ; RAMOS; HINGEL, 2007, p. 18).

Conforme aponta Scheibe (2011), a reformulação das funções da Capes, que passou a subsidiar o MEC também na formulação de políticas e no desenvolvimento de atividades de suporte à formação de profissionais de magistério para a educação básica, pode ser vista como mais uma sinalização no sentido da "responsabilização da União pela formação de profissionais do magistério da educação básica, historicamente tratada sem prioridade pelo poder público nacional" (p. 814). Essa responsabilização não só apresenta medidas em direção à descentralização, afirmando o princípio federativo, como também promove um movimento de recentralização das políticas educacionais, no qual o Executivo federal dita as normas para a redefinição de responsabilidades, ampliando funções de controle de qualidade, avaliação e definições de padrões curriculares (SCHEIBE, 2011).

Outro aspecto que merece destaque nessa reconfiguração da Capes é a atuação do CTC da Educação Básica, que passou a discutir, logo em suas primeiras reuniões, a necessidade de 
criação de um Sistema Nacional de Formação de Professores. Essa missão foi a principal atividade à qual se dedicou o conselho ao longo de 2008 (SCHEIBE, 2008). Assim, foi gestada a concepção de uma "Política Nacional de Formação de Profissionais da Educação Básica" que resultaria num decreto público em 2009.

\section{A Política Nacional de Formação dos Profissionais da Educação Básica e sua institucionalização: um olhar sobre os decretos de sua regulamentação}

Outra ação encaminhada pelo Executivo federal no campo da formação de professores, cuja formulação se deu no interior do CTC da Capes, foi a regulamentação e instituição da "Política Nacional de Formação de Profissionais do Magistério da Educação Básica", que teve como marco inicial a formulação e publicação do Decreto $n^{\circ} 6.755$, de 29 de janeiro de $2009^{12}$.

Já em seu art. $1^{\circ}$, o decreto aponta para uma perspectiva no sentido de que a formação de professores demandaria uma ação articulada entre os entes da federação ao estabelecer que essa política teria como finalidade "organizar, em regime de colaboração entre a União, os Estados, o Distrito Federal e os Municípios, a formação inicial e continuada dos profissionais do magistério para as redes públicas da educação básica". Em seguida foram definidos os princípios orientadores da Política Nacional de Formação ${ }^{13}$ :

I - a formação docente para todas as etapas da educação básica como compromisso público de Estado, buscando assegurar o direito das crianças, jovens e adultos à educação de qualidade, construída em bases científicas e técnicas sólidas;

II - a formação dos profissionais do magistério como compromisso com um projeto social, político e ético que contribua para a consolidação de uma nação soberana, democrática, justa, inclusiva e que promova a emancipação dos indivíduos e grupos sociais;

III - a colaboração constante entre os entes federados na consecução dos objetivos da Política Nacional de Formação de Profissionais do Magistério da Educação Básica, articulada entre o Ministério da Educação, as instituições formadoras e os sistemas e redes de ensino;

${ }^{12}$ A proposta inicial apresentada pelo Ministério da Educação ao CTC da Educação Básica/Capes para a criação de um sistema nacional de formação de profissionais de magistério para a educação básica foi amplamente discutida, porém não se concretizou, por ter predominado o entendimento, entre os conselheiros, de que não caberia tal definição antes da construção de um efetivo Sistema Nacional de Educação, já em pauta para a Conferência Nacional de Educação - Conae realizada em 2010. (SCHEIBE, 2011).

${ }^{13}$ Neste trabalho, a expressão Política Nacional de Formação, sempre que registrada em itálico, estará relacionada à Política Nacional de Formação dos Profissionais do Magistério da Educação Básica, regulada, inicialmente, pelos Decretos no 6.755/2009 e 7.415/2010, posteriormente alterada para Política Nacional de Formação dos Profissionais da Educação Básica, por meio do Decreto no 8.752/2016.

RPGE- Revista on line de Política e Gestão Educacional, Araraquara, v. 23 n. 3, p. 498-522, set./dez., 2019. E-ISSN: 1519-9029. DOI: $10.22633 /$ rpge.v23i3.12526 
IV - a garantia de padrão de qualidade dos cursos de formação de docentes ofertados pelas instituições formadoras nas modalidades presencial e à distância;

V - a articulação entre a teoria e a prática no processo de formação docente, fundada no domínio de conhecimentos científicos e didáticos, contemplando a indissociabilidade entre ensino, pesquisa e extensão;

VI - o reconhecimento da escola e demais instituições de educação básica como espaços necessários à formação inicial dos profissionais do magistério; VII - a importância do projeto formativo nas instituições de ensino superior que reflita a especificidade da formação docente, assegurando organicidade ao trabalho das diferentes unidades que concorrem para essa formação e garantindo sólida base teórica e interdisciplinar;

VIII - a importância do docente no processo educativo da escola e de sua valorização profissional, traduzida em políticas permanentes de estímulo à profissionalização, à jornada única, à progressão na carreira, à formação continuada, à dedicação exclusiva ao magistério, à melhoria das condições de remuneração e à garantia de condições dignas de trabalho;

IX - a equidade no acesso à formação inicial e continuada, buscando a redução das desigualdades sociais e regionais;

$X$ - a articulação entre formação inicial e formação continuada, bem como entre os diferentes níveis e modalidades de ensino;

XI - a formação continuada entendida como componente essencial da profissionalização docente, devendo integrar-se ao cotidiano da escola e considerar os diferentes saberes e a experiência docente; e

XII - a compreensão dos profissionais do magistério como agentes formativos de cultura e, como tal, da necessidade de seu acesso permanente a informações, vivência e atualização culturais.

De um lado, esse momento pode ser visto como o ponto alto da centralidade que a formação de professores veio ganhando desde a década de 1990, resguardadas as significativas diferenças na concepção e condução das ações em torno dessa centralidade, implementadas nos governos que se sucederam desde então (1990-2001; 2002-2014). Por outro lado, a redefinição dos modos de organização e atuação do Estado no desenvolvimento das políticas sociais produziu importantes determinações que, por sua vez, geraram possibilidades de constituição de mediações políticas minimamente democráticas, diferentes das que predominaram em períodos autoritários.

Os compromissos que o Estado brasileiro passou a ter com a garantia do direito à educação reafirmaram também a necessidade de uma política de valorização e formação de professores sustentada na participação dos entes federativos. O regime de colaboração teve que ser "enfrentado" no sentido de se buscar caminhos para sua efetivação dentro do modelo de federalismo definido constitucionalmente.

O Decreto $^{\circ} 6.755 / 2009$ coloca em evidência o papel das instituições formadoras e seus projetos formativos, que devem garantir a qualidade da formação por meio da indissociabilidade entre ensino, pesquisa e extensão e da articulação entre formação inicial e 
continuada. Além disso, na esteira do que vinha sendo proposto em ações como o Pibid e a Renafor, cada vez mais se busca uma articulação entre formação inicial e formação continuada, o que, por sua vez, exige a aproximação entre instituições formadoras e redes de ensino. Nesse contexto, busca-se uma perspectiva de profissionalização que tem na escola o locus privilegiado para o desenvolvimento tanto do docente em exercício, que deve ser valorizado e reconhecido como agente de cultura, quanto dos estudantes das licenciaturas, que devem compreender o papel das escolas em sua formação.

Ao atentarmos para os objetivos da Política Nacional de Educação, identificamos que eles abordam, ou tangenciam, as principais problemáticas que a formação de professores tem enfrentado e que têm sido objeto de inúmeras análises e reflexões na produção de conhecimento desse campo: a questão da qualidade da formação de professores e sua relação com a qualidade da educação básica; a demanda por docentes em número suficiente para atender as instituições públicas, articulando-se a isso a necessária equalização nacional das oportunidades de formação; a valorização do docente, que diz respeito ao seu ingresso, permanência e progressão na carreira em condições adequadas; as políticas voltadas para grupos e minorias no âmbito da diversidade, com a perspectiva da garantia dos direitos humanos; e o investimento em atualização teórico-metodológica dos processos de formação.

Para a consecução dos objetivos da Política Nacional de Formação na interface com a perspectiva da construção do regime de colaboração, o Decreto $n^{\circ} 6.755 / 2009$ instituiu os Fóruns Permanentes de Apoio à Formação Docente, que deveriam ser criados e instalados em cada estado e no Distrito Federal, e esses fóruns teriam como tarefa central a formulação, o acompanhamento e a revisão periódica do plano estratégico para o campo da formação dos profissionais do magistério no respectivo âmbito de atuação - estadual ou distrital $\left(\S 1^{\circ}\right.$ e $6^{\circ}$, art. $\left.4^{\circ}\right)$.

A composição dos Fóruns Permanentes deveria contemplar representações dos seguintes segmentos: Ministério da Educação (um representante); secretários Municipais de Educação (dois representantes); instituições públicas de educação superior (um de cada instituição); Conselho Estadual de Educação (um representante); União Nacional dos Conselhos Municipais de Educação - Uncme (um representante); profissionais do magistério indicados pela seção sindical da CNTE (um representante); Fóruns de Licenciatura das IES públicas (se houvesse). O secretário de Educação do Estado, ou do Distrito Federal, conforme cada caso, ao lado de mais um representante dessa secretaria, também comporia o Fórum Permanente, sendo aquele que exerceria a Presidência do Fórum. 
À exceção da Secretaria de Educação, todos os demais órgãos, entidades ou instituições com assento previsto no Fórum somente teriam sua participação confirmada mediante formalização de sua adesão a essa nova instituição recém-criada $\left(\S 2^{\circ}, 3^{\circ}, 4^{\circ}\right.$ e $5^{\circ}$, art. $\left.4^{\circ}\right)$. A ausência dessa confirmação por parte de qualquer dos possíveis membros não seria um impeditivo para a instalação e o funcionamento do Fórum. Admitia-se, ainda, a atuação de outras participações institucionais mediante apresentação de outras demandas de adesão.

O plano estratégico a ser elaborado pelo Fórum Permanente de Apoio à Formação Docente deveria contemplar:

I - diagnóstico e identificação das necessidades de formação de profissionais do magistério e da capacidade de atendimento das instituições públicas de educação superior envolvidas;

II - definição de ações a serem desenvolvidas para o atendimento das necessidades de formação inicial e continuada, nos diferentes níveis e modalidades de ensino; $\mathrm{e}$

III - atribuições e responsabilidades de cada partícipe, com especificação dos compromissos assumidos, inclusive financeiros. (Art. $5^{\circ}$ )

Nesse diagnóstico, por um lado, deveriam estar discriminados, com base nos dados do Censo da Educação Básica, pelo menos os seguintes dados relativos aos profissionais do magistério:

I - os cursos de formação inicial;

II - os cursos e atividades de formação continuada;

III - a quantidade, o regime de trabalho, o campo ou a área de atuação dos profissionais do magistério a serem atendidos; $\mathrm{e}$

IV - outros dados relevantes que complementem a demanda formulada $\left(\S 1^{\circ}\right.$ art. $5^{\circ}$ ).

Por outro lado, para o planejamento e a organização do atendimento das necessidades, o plano estratégico deveria considerar os dados do censo da educação superior $\left(\S 2^{\circ} \operatorname{art.} 5^{\circ}\right)$.

Ao final desse processo de planejamento, caberia ao MEC analisar e aprovar os planos estratégicos apresentados (art. $6^{\circ}$ ) e definir a maneira de sua atuação na formação inicial e continuada dos profissionais do magistério, considerando duas as possibilidades previstas nesse mesmo decreto:

I - concessão de bolsas de estudo e bolsas de pesquisa para professores, na forma da Lei $\mathrm{n}^{\circ} 11.273$, de 6 de fevereiro de 2006, bem como auxílio a projetos relativos às ações referidas no caput; e

II - apoio financeiro aos Estados, Distrito Federal, Municípios e às instituições públicas para implementação de programas, projetos e cursos de formação. $\left(\operatorname{art.} 9^{\circ}\right)$ 
A funcionalidade e a forma de ser dos fóruns, assim como de outros espaços, como as conferências e os conselhos, deveriam ser compreendidas como processos de captação de demandas da sociedade civil que poderiam ou não ser assimiladas pelo Estado. A elaboração de respostas a essas reivindicações resultariam em políticas públicas que, por sua vez, expressariam o que podemos chamar de governo em ação.

Considerando que a sociedade civil é um complexo de determinações eivado de contradições, conflitos ou possibilidades de confluência, há de se entender que dela emerge uma pluralidade de perspectivas, interesses, confluências e divergências que se expressa acerca, praticamente, de todos os temas relacionados ao que se canaliza para o Estado, notadamente para o Poder Executivo. Isso possui validade para todas as dimensões da vida social em que, de uma forma ou de outra, se coloca a possibilidade de elaboração de alguma política de governo.

Se, por um lado, o governo federal procurou atuar na promoção e na condução de uma Política Nacional de Formação envolvendo os estados e municípios e os setores da sociedade civil, buscando recuperar certo protagonismo perdido na definição das políticas educativas em âmbito nacional pelas reformas ocorridas nas décadas passadas; por outro, também tem reduzido as possibilidades de autonomia e autodeterminação dos governos subnacionais.

A composição definida no Decreto $n^{\circ} 6.755 / 2009$ para os Fóruns Estaduais permitiria que, de fato, eles fossem espaços de concertação suscetíveis à atuação de movimentos, representantes de concepções, de entidades e de outros arranjos institucionais admitidos em uma sociedade democrática, com vistas ao encaminhamento de demandas e, ao retorno, de respostas. Desde que haja uma efetiva capilaridade na sociedade civil por parte desses espaços de concertação social, a eles estaria posta a possibilidade de influenciar a direção, a orientação que o Estado confere a cada política formulada, inclusive no que tange aos vários níveis (municipal, estadual ou distrital e nacional) de formulação e aplicação da política correlata.

Daí a se ter, concretamente, a elaboração de um planejamento estratégico, pode haver um longo caminho a percorrer. A mera existência de fóruns, conferências e conselhos não garante, por si só, que programas ou ações eventualmente pontuais adquiram a configuração de uma política de Estado pactuada com as forças sociais que predominam, ou que logram a condição de hegemônicas. Contudo, essa articulação não pode ser dependente de arranjos governamentais, que oscilam de acordo com as posições políticas assumidas, as composições partidárias e outros fatores intervenientes nessas relações.

Especificamente em relação à formação continuada de professores, fica evidente na Política Nacional de Formação delineada no Decreto 6.755/2009 a ênfase no sentido de que 
essa formação continuada se realize pela via da oferta de cursos e atividades formativas por instituições públicas de educação, cultura e pesquisa, como bem evidenciado no seu art. $8^{\circ}$ :

Art. $8^{\circ} \mathrm{O}$ atendimento às necessidades de formação continuada de profissionais do magistério dar-se-á pela indução da oferta de cursos e atividades formativas por instituições públicas de educação, cultura e pesquisa, em consonância com os projetos das unidades escolares e das redes e sistemas de ensino.

$\S 1^{\circ} \mathrm{A}$ formação continuada dos profissionais do magistério dar-se-á por meio de cursos presenciais ou cursos à distância.

$\S 2^{\circ}$ As necessidades de formação continuada de profissionais do magistério serão atendidas por atividades formativas e cursos de atualização, aperfeiçoamento, especialização, mestrado ou doutorado.

$\S 3^{\circ}$ Os cursos de atualização, aperfeiçoamento e especialização serão fomentados pela Coordenação de Aperfeiçoamento de Pessoal de Nível Superior - CAPES, deverão ser homologados por seu Conselho TécnicoCientífico da Educação Básica e serão ofertados por instituições públicas de educação superior, preferencialmente por aquelas envolvidas no plano estratégico de que tratam os arts. $4^{\circ}$ e $5^{\circ}$.

$\S 4^{\circ}$ Os cursos de formação continuada homologados pelo Conselho TécnicoCientífico da Educação Básica da CAPES integrarão o acervo de cursos e tecnologias educacionais do Ministério da Educação.

$\S 5^{\circ}$ Caso a necessidade por formação continuada não possa ser atendida por cursos já homologados na forma do $\S 4^{\circ}$, a CAPES deverá promover o desenvolvimento de projetos político-pedagógicos específicos, em articulação com as instituições públicas de educação superior.

$\S 6^{\circ}$ A CAPES disporá sobre requisitos, condições de participação e critérios de seleção de instituições e de projetos pedagógicos específicos a serem apoiados.

Ainda que se reconheça o avanço apontado nesse novo marco regulatório do campo da formação de professores no intuito de dar mais visibilidade à questão da formação continuada como elemento constitutivo da formação docente, chama atenção a forte ênfase no sentido de essa formação se realizar por meio de cursos de diferentes naturezas, níveis e modalidades. Princípios formativos que destacavam a escola como espaço de formação acabaram por serem esquecidos ou, pelo menos, secundarizados.

Outros movimentos importantes possíveis de serem apreendidos na análise do Decreto 6.755/2009 é o fato de programas e ações serem incorporados como parte da Política Nacional de Formação. Destaca-se, dessa forma, a assimilação do Pibid e do Prodocência, assumidos como uma das estratégias de atuação da Capes nessa Política. (art. 10 e 11, inciso I), mas o decreto prevê, ainda, outras possibilidades de atuação da Capes no fomento de ações como:

Art. 11 A CAPES fomentará ainda:

$[\ldots]$

II - projetos pedagógicos que visem a promover desenhos curriculares próprios à formação de profissionais do magistério para atendimento da 
educação do campo, dos povos indígenas e de comunidades remanescentes de quilombos;

III - oferta emergencial de cursos de licenciaturas e de cursos ou programas especiais dirigidos aos docentes em exercício há pelo menos três anos na rede pública de educação básica, que sejam:

a) graduados não licenciados;

b) licenciados em área diversa da atuação docente; e

c) de nível médio, na modalidade Normal;

IV - projetos de revisão da estrutura acadêmica e curricular dos cursos de licenciatura;

$\mathrm{V}$ - pesquisas destinadas ao mapeamento, aprofundamento e consolidação dos estudos sobre perfil, demanda e processos de formação de profissionais do magistério;

VI - programas de apoio a projetos educacionais e de pesquisa propostos por instituições e por profissionais do magistério das escolas públicas que contribuam para sua formação continuada e para a melhoria da escola; e VII - programas que promovam a articulação das ações de formação continuada com espaços de educação não-formal e com outras iniciativas educacionais e culturais.

Tem-se, pois, novos indícios de um movimento no sentido de se alcançar uma visão e organização sistêmicas no campo da formação de professores. No entanto fica evidente não só a multiplicidade de caminhos para os quais essa Política apontava no campo da formação continuada do professor, mas também o destaque que a formação de professores - formação continuada - ocupou na atuação do Estado brasileiro.

Orientado pelo Decreto 6.755/2009, o MEC editou e publicou duas portarias por meio das quais procurou delimitar aspectos operacionais e organizacionais para se criar condições institucionais no âmbito daquele órgão para que a Política da Nacional da Formação avançasse do plano das orientações para a ação organizacional para o plano da ação organizacional (LIMA, 2001).

Em 2010, foi publicado mis um decreto concernente à Política Nacional de Formação (Decreto $\mathrm{n}^{\circ} 7.415$, de 30 de dezembro de 2010) que, sem revogar o Decreto 6.755/2009, trouxe um novo elemento para essa política: o programa Profuncionário, incorporado como uma das ações constitutivas dessa política que passou a ter sua denominação mais ampliada como Política Nacional de Formação dos Profissionais da Educação Básica. Ou seja, com essa mudança, a atuação do Estado no campo da formação era, mais uma vez, assumida como abrangendo não apenas os que atuavam no magistério, mas também todos aqueles que atuavam na educação escolar.

Oito meses mais tarde, por meio da Portaria MEC $\mathrm{n}^{\circ} 1.087$, de 10 de agosto de 2011, o MEC implementou mais uma iniciativa no campo da formação dos profissionais da educação e da Política Nacional da Formação por intermédio da constituição do "Comitê Gestor da Política 
Nacional de Formação Inicial e Continuada de Profissionais da Educação Básica”. Esse comitê teria como atribuições:

I - propor diretrizes pedagógicas e definir cursos de formação inicial e continuada de profissionais da educação básica a serem ofertados às redes de educação básica;

II - aprovar os planos estratégicos elaborados pelos Fóruns Estaduais Permanentes de Apoio à Formação Docente, de que tratam os arts. $4^{\circ}, 5^{\circ}$ e $6^{\circ}$ do Decreto 6.755, de 29 de janeiro de 2009;

III - analisar a demanda e organizar a oferta dos cursos nos estados onde o Fórum Estadual Permanente de Apoio à Formação Docente não elaborar o plano estratégico;

IV - definir, com base em custo/aluno por curso, montante de recursos orçamentários a ser alocado para implementação das ações de formação inicial e continuada de profissionais da educação básica;

V - disponibilizar sistema de informação a ser utilizado pelas redes de ensino e Fóruns Estaduais Permanentes de Apoio à Formação Docente para o planejamento e monitoramento das ações de formação inicial e continuada dos profissionais da educação básica;

VI - indicar os representantes do MEC nos Fóruns Estaduais Permanentes de Apoio à Formação Docente, de que trata art. $4^{\circ}, \S 1^{\circ}$, II do Decreto $n^{\circ} .6 .755$, de 29 de janeiro de 2009;

VII - monitorar e avaliar os programas de formação inicial e continuada financiados pelo MEC, CAPES e FNDE. (art. $3^{\circ}$ )

Em sua composição, além do secretário executivo do MEC, que presidia esse comitê, participariam, também, os titulares dos seguintes órgãos:

I. Secretaria de Educação Básica (SEB);

II. Secretaria de Educação Continuada, Alfabetização, Diversidade e Inclusão (SECADI);

III. Secretaria de Educação Superior (SESU);

IV. Secretaria de Educação Profissional e Tecnológica (SETEC); V.Secretaria de Articulação com os Sistemas de Ensino (SASE);

VI. Coordenação de Aperfeiçoamento de Pessoal de Nível Superior (CAPES); e

VII. Fundo Nacional de Desenvolvimento da Educação (FNDE).

Em 2011, por meio da Resolução n ${ }^{\circ}$ 01, de 17 de agosto de 2011, do Comitê Gestor Nacional, o MEC determinou a criação, em cada instituição que desejasse aderir às ações e aos recursos provenientes da Política Nacional de Formação, de um Comitê Gestor Institucional com a tarefa de "indução à articulação, à coordenação e à organização de programas e ações de formação inicial e continuada de profissionais do magistério da educação básica, bem como pela gestão e execução de recursos recebidos por meio do apoio financeiro previsto no caput." $\left(\S 1^{\circ}\right.$; art. 17). 
Esses novos marcos regulatórios da Política Nacional de Formação nos possibilitam apreender e compreender os contornos que ela foi assumindo no âmbito de sua regulação. Destaca-se, inicialmente, que a intervenção direta do Executivo federal por meio de decretos reforça a interpretação de que se trata da vinculação dessa política com a perspectiva do governo, não sendo, portanto, uma política de Estado. A estratégia de manter as diretrizes e as ferramentas de operacionalização de um conjunto grande de ações que deveria compor os planos de ação dos estados e municípios, sob o controle de uma instância de dentro do Ministério, o "Comitê Gestor da Política Nacional de Formação Inicial e Continuada de Profissionais da Educação Básica”, demonstra que o caráter regulador estava se aprofundando.

Outro elemento de análise que emerge desse cenário de reconfiguração da atuação do Estado no campo da formação diz respeito aos desdobramentos da centralização da política no âmbito da Capes. A tarefa de subsidiar o Ministério da Educação na formulação de políticas e no desenvolvimento de atividades de suporte à formação de profissionais de magistério para a educação básica, prevista na Lei n ${ }^{\circ} 11.502 / 2007$, se desdobrou em um conjunto diversificado de responsabilidades elencado no Decreto $\mathrm{n}^{\circ} 7.692 / 2007$, que aprovou o novo estatuto da Capes, que previa a constituição de um Sistema Nacional de Formação.

Num primeiro momento, essa transferência de tarefas acabou produzindo uma sobreposição de determinadas atribuições entre os diversos setores do Ministério da Educação e o próprio conselho em relação aos projetos de formação em andamento, como novas normatizações e determinações anteriores ainda prevalecentes e em conflito com aquelas arroladas no estatuto da Capes (SCHEIBE, 2011). Nas análises de Souza (2016) sobre os desafios na condução da Política Nacional de Formação, mais alguns elementos revelam um início conturbado dessa nova trajetória de ação da Capes:

A proposta do sistema de formação, estabelecida na minuta do CTC-EB, implicaria mexer com as bases da compartimentalização das ações do MEC entre seus órgãos vinculados - Capes, CNE e Inep - em prol da formação docente. Talvez, em função disso, tenha ocorrido certa mobilização interna para frear a proposta original (...).

(...) Se implementada, tal competência poderia concorrer com as atribuições do próprio CNE e implicaria a adoção de um sistema avaliativo paralelo ao do Sinaes, específico para as licenciaturas.

A elaboração dos dois decretos que instituíram a Política Nacional de Formação se deu, portanto, nesse período de ajustes na nova configuração da estrutura organizacional da Capes, ao mesmo tempo em que sua atuação representou uma linha de ação marcada pela continuidade dos programas. Os dois decretos tratados aqui (6.755/2009 e 7.415/2010) foram posteriormente 
revogados pelo Decreto $\mathrm{n}^{\circ}$ 8.752, de 9 de maio de 2016, que “dispõe sobre a Política Nacional de Formação dos Profissionais da Educação Básica, fixando seus princípios e objetivos, e organizando seus programas e ações, em regime de colaboração entre os sistemas de ensino e em consonância com o Plano Nacional de Educação - PNE/2014”. Entretanto, como desdobramento da conflituosa conjuntura política instalada com o afastamento da presidenta Dilma Roussef nesse mesmo ano, seguido de seu impeachment, ficou seriamente comprometida a continuidade dessa concepção de formação nos moldes pelos quais vinha sendo construída por meio desses ordenamentos legais.

\section{Considerações finais}

No campo da formação dos profissionais de educação básica é possível apreender que se, por um lado, o relativo "êxito" do ideário neoliberal orientou as políticas de formação dos profissionais da educação básica, na medida em que nos defrontamos com o avanço, no âmbito das ideias, do uso de conceitos e categorias próprios desse ideário, como, por exemplo, eficácia, eficiência, qualidade total, competências, dentre outros. Por outro lado, esse êxito decorreu, também, de constrangimentos orçamentários produzidos pelos acordos com os organismos internacionais que passaram a financiar parte significativa das políticas educacionais no país, especialmente até os anos de 2004 e 2005.

Em contrapartida, é preciso reconhecer, igualmente, que a partir de 2006 e 2007, novos contornos foram produzidos no campo das políticas de formação dos profissionais da educação básica, nos quais ficou evidente a busca por uma maior articulação dessas ações e de programas que sustentavam tais políticas, na tentativa de se alcançar maior organicidade nesse campo, ainda que se fizesse presente algum grau de dispersão. É o que nos evidenciam os dados analisados sobre o desenho político-institucional que assumiu a "Política Nacional de Formação dos Profissionais da Educação Básica" e a "Rede Nacional de Formação Continuada dos Profissionais da Educação Básica", em que a constituição de "comitês gestores" objetivava assegurar tal organicidade, como alternativa para superação da fragmentação presente no âmbito das políticas de formação.

Na mesma direção, o próprio Plano de Desenvolvimento da Educação também expressou esse esforço, ainda que o caráter de multidimensionalidade se faça igualmente nele presente. Esse caráter multidimensional resulta, em boa medida, do fato de que o que se presenciou foi um esforço dos governos de Lula e Dilma para incorporarem novas 
possibilidades e frentes de atuação do Estado no campo da formação, sem, necessariamente, abandonar outros caminhos que vinham sendo trilhados.

Do mesmo modo, em oposição ao foco que predominou nos anos 1990 e início dos anos 2000, em que a lógica de políticas direcionadas ao campo da formação dos profissionais da educação privilegiou aqueles que atuavam no ensino fundamental e, mais especificamente, nos anos iniciais dessa etapa de escolarização, agora, com a nova lógica, passaram a se instalar nesse campo os programas de formação, que alcançaram, também, outros segmentos no âmbito da educação básica.

Nos contornos e no desenvolvimento do campo das políticas de formação dos profissionais da educação básica é possível apreender e compreender, também, o lugar e o papel que os órgãos e estruturas de governo vão assumindo nessas políticas, visto que eles expressam determinadas concepções de organização do Estado na sociedade. Observa-se um reposicionamento do Executivo federal nos debates e na discussão ocorridos a partir dos anos de 2005, com uma maior assimilação de formulações e propostas oriundas do debate acadêmico e político da área, como é o caso do reconhecimento da necessidade de uma política nacional de formação.

A discussão sobre o processo de formulação e implementação de políticas públicas não é linear, mas sim marcado por dinâmicas determinadas pela totalidade social e pelas mediações que conformam as singularidades que o campo implica, resultantes da correlação de forças dos atores sociais coletivos envolvidos ou alcançados por essas políticas. Essas características implicam a busca e a capacidade de construção de consensos, o que demanda o indispensável diálogo e a participação da sociedade civil organizada.

Sem dúvida, numa sociedade como a nossa, marcada por interesses antagônicos de classe, os limites na construção de pactos sobre as políticas públicas em geral, e sobre as políticas de formação em particular, permitem compreender os percalços para se avançar na direção de "políticas de governo" para "políticas de Estado".

Por sua vez, caminhar na direção da constituição e do fortalecimento das políticas de Estado demanda, ainda, a existência de órgãos e espaços institucionais que favoreçam e contribuam para a continuidade daquelas políticas que resultaram de processos amplos e democráticos de discussão, elaboração e implementação. Esses órgãos e espaços acabam por assumir um papel igualmente importante no sentido de se constituírem em instâncias de controle social e de participação política. Esse é o horizonte a ser construído em órgãos como 
o Conselho Nacional de Educação na perspectiva de que venham a se tornarem órgãos de Estado, e não apenas instâncias ou órgãos de governo.

Sendo assim, os contornos delineados no contexto da regulamentação da política nacional de formação dos profissionais da educação, desde a reconfiguração da Capes, em 2007, para a Formação Inicial e Continuada de Professores da Educação Básica, expressam a perspectiva de se garantirem canais de interlocução e controle social com diferentes segmentos da sociedade civil participando deles. Confirmam essa perspectiva a constituição de espaços como os "Fóruns Estaduais de Apoio à Formação Docente"; os "Comitês Gestores" nacional e institucionais; a concepção de "Rede de Formação", que foi reformulada nesse período, dentre outros elementos. Em síntese, os ordenamentos jurídicos e organizacionais produzidos apontam tanto para o que “deve ser”, no plano das orientações para a ação, quanto assimila elementos da realidade em que estão presentes diferentes posicionamentos, perspectivas e propostas em disputa.

Por último, os programas e as ações implementados no campo da formação de professores no período mostram as diferentes nuances que as relações federativas assumiram no campo da formação de professores, sempre marcadas, com maior ou menor ênfase, por um movimento do governo central induzindo e conduzindo as políticas nesse campo, restando aos governos locais tarefas de natureza mais operacionais. Nessas bases, o regime de colaboração e as relações interfederativas que se constroem no campo da formação de professores são, predominantemente, orientados do centro para a margem, em processos muitos mais de desconcentração do que, efetivamente, de descentralização.

\section{REFERÊNCIAS}

ALVES, G. Neodesenvolvimentismo e precarização do trabalho no Brasil. Parte I. Blog da Boitempo. 20/05/2013. Disponível em: http://blogdaboitempo.com.br/2013/05/20/neodesenvolvimentismo-eprecarizacao-dotrabalho-no-brasil-parte-i/. Acesso em: 23 jan. 2018.

BRASIL. Decreto $\mathbf{n}^{0}$ 6.094 de 24 de maio de 2007. Dispõe sobre a implementação do Plano de Metas Compromisso Todos pela Educação, pela União Federal, em regime de colaboração com Municípios, Distrito Federal e Estados, e a participação das famílias e da comunidade, mediante programas e ações de assistência técnica e financeira, visando a mobilização social pela melhoria da qualidade da educação básica. Disponível em: http://www.planalto.gov.br/ccivil_03/_ato2007-2010/2007/decreto/d6094.htm. Acesso em: 12 jan. 2019. 
BRASIL. Lei $\mathbf{n}^{\circ} \mathbf{1 1 . 5 0 2}$ de 11 de julho de 2007. Modifica as competências e a estrutura organizacional da fundação Coordenação de Aperfeiçoamento de Pessoal de Nível Superior CAPES, de que trata a Lei $n^{\circ} 8.405$, de 9 de janeiro de 1992. Disponível em:

http://www.planalto.gov.br/ccivil_03/_ato2007-2010/2007/lei/111502.htm. Acesso em: 18 jan. 2018.

BRASIL. Decreto $\mathbf{n}^{\mathbf{0}}$ 6.316, de 20 de dezembro de 2007. Aprova o Estatuto e o Quadro Demonstrativo dos Cargos em Comissão da Coordenação de Aperfeiçoamento de Pessoal de Nível Superior - CAPES, e dá outras providências. Disponível em: http://www.planalto.gov.br/ccivil_03//_Ato2007-2010/2007/Decreto/D6316impressao.htm. Acesso em: 15 ago. 2018.

BRASIL. Decreto no 6.755 de 29 de janeiro de 2009. Institui a Política Nacional de Formação de Profissionais do Magistério da Educação Básica, disciplina a atuação da Coordenação de Aperfeiçoamento de Pessoal de Nível Superior - CAPES no fomento a programas de formação inicial e continuada, e dá outras providências. Disponível em: http://www.planalto.gov.br/ccivil_03/_ato2007-2010/2009/decreto/d6755.htm. Acesso em: 30 set. 2018.

BRASIL. Decreto no 7.415 de 30 de dezembro de 2010. Institui a Política Nacional de Formação dos Profissionais da Educação Básica, dispõe sobre o Programa de Formação Inicial em Serviço dos Profissionais da Educação Básica dos Sistemas de Ensino Público - Profuncionário, e dá outras providências. Brasília, 31 de dezembro de 2010. Disponível em: http://www.planalto.gov.br/ccivil_03/_ato20072010/2010/decreto/d7415.htm. Acesso em: 24 mar. 2018.

BRASIL. Portaria MEC no 1.087 de 10 de agosto de 2011. Institui o Comitê Gestor da Política Nacional de Formação Inicial e Continuada de Profissionais da Educação Básica e define suas diretrizes gerais. Disponível em: https://www.capes.gov.br/images/stories/download/legislacao/Portaria-MEC-1087ComiteGestor.pdf. Acesso em: 17 out. 2018.

BRASIL. Resolução $\mathbf{n}^{0} 1$ de 17 de agosto de 2011. Comitê Gestor da política nacional de formação inicial e continuada de profissionais da educação básica. Disponível em: http://portal.mec.gov.br/index.php?option=com_docman\&view=download\&alias=9943resolucao-1-17-agosto-2011\&category_slug=fevereiro-2012-pdf\&Itemid=30192. Acesso em: 17 jul. 2018.

BRASIL. Decreto no 7.692 de 2 de março de 2012. Aprova o Estatuto e o Quadro Demonstrativo dos Cargos em Comissão da Coordenação de Aperfeiçoamento de Pessoal de Nível Superior - CAPES, e remaneja cargos em comissão. Disponível em: http://www.planalto.gov.br/ccivil_03/_Ato2011-2014/2012/Decreto/D7692impressao.htm. Acesso em: 18 set. 2018.

BRASIL. Decreto n ${ }^{0} 8.752$ de 9 de maio de 2016. Dispõe sobre a Política Nacional de Formação dos Profissionais da Educação Básica. Disponível em: http://www.planalto.gov.br/ccivil_03/_ato2015-2018/2016/decreto/d8752.htm. Acesso em: 8 jun. 2017. 
CAMINI, L. A política educacional do PDE e do Plano de Metas Compromisso Todos pela Educação. Revista Brasileira de Política e Administração da Educação (RBPAE), Recife, v. 26. n. 3, p. 409-640, set./dez. 2010.

DOURADO, L. F. Políticas e gestão da educação básica no Brasil: limites e perspectivas. Educação \& Sociedade, Campinas, v. 28, n. 100 - Especial, p. 921-946, out., 2007.

LIMA, L. C. A escola como organização educativa: uma abordagem sociológica. São Paulo: Cortez, 2001

MARTINS, A. S. A educação básica no século XXI. O projeto do organismo "Todos pela Educação". Práxis Educativa, Ponta Grossa, v. 4, n. 1, jan./jun. 2009.

RUIZ, A. I; RAMOS, M. N.; HINGEL, M. Escassez de professores no Ensino Médio: propostas estruturais e emergenciais. Relatório produzido pela Comissão Especial instituída para estudar medidas que visem a superar o déficit docente no Ensino Médio (CNE/CEB). Brasília, DF: MEC; CNE; CEB, 2007. Disponível em:

http://portal.mec.gov.br/cne/arquivos/pdf/escassez1.pdf. Acesso em: 19 maio 2017.

SCHEIBE, L. Formação de professores no Brasil: A herança histórica. Revista Retratos da Escola, Brasília, v. 2, n. 2-3, p. 41-53, jan./dez. 2008. Disponível em:

http://www.cnte.org.br/images/stories/2012/revista_retratosdaescola_02_03_2008_formacao_ professores.pdf. Acesso em: 12 jan. 2018.

SCHEIBE, L. O conselho técnico-científico da educação básica da CAPES e a formação docente. Cadernos de Pesquisa, São Paulo, v. 41, n. 144, p. 812-825, 2011.

SIMIÃO, L. N.; DA SILVA, A. L.; DE LIMA, B. M. Neodesenvolvimentismo: "uma velha roupa colorida?": uma análise crítica das políticas sociais para as cidades. Revista SER Social, v. 16, n. 35, p. 354, mar. 2015. Disponível em: http://periodicos.unb.br/index.php/SER_Social/article/view/10570. Acesso em: 20 jun. 2018.

SOUZA, A. R. A política educacional e seus objetos de estudo. Revista de Estudios teóricos y Epistemológicos en Política Educativa, v. 1, n. 1, p. 75-89. 2016.

TORRIGLIA, P. L.; ORTIGARA, V. O campo de mediações: primeiras aproximações para a pesquisa em políticas educacionais. In: SOUZA, J. V. DE; SILVA, M. A. DA. (Orgs.). O método dialético na pesquisa em educação. Campinas, SP: Autores Associados/Brasília, DF: Universidade de Brasília, 2014. 


\section{Como referenciar este artigo:}

AMARAL, Gislene Alves; SILVA, Marcelo Soares Pereira. Gênese da política nacional de formação no contexto das reconfigurações do Estado brasileiro no período de 2007 a 2010. Revista on line de Política e Gestão Educacional, Araraquara, v. 23 n. 3, p. 498-522, set./dez., 2019. E-ISSN: 1519-9029. DOI: 10.22633/rpge.v23i3.12526

Submetido em: 06/06/2019

Revisões requeridas: 10/07/2019

Aprovado em: 30/07/2019

Publicado em: 15/08/2019 